
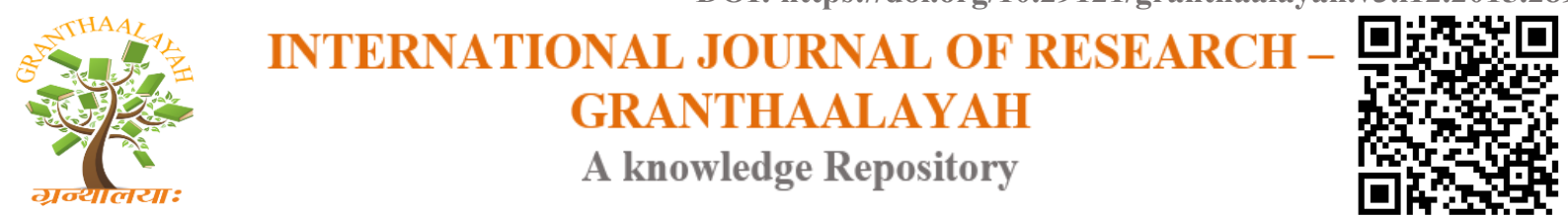

Management

\title{
HOW VOLATILE IS INDIAN STOCK MARKET? A STUDY BASED ON SELECTED SECTORAL INDICES
}

\author{
T. Mohamed Nishad ${ }^{1}$, K.T. Thomachan ${ }^{2}$ \\ ${ }^{1}$ Assistant Professor, Department of Commerce, Farook College, Kozhikode, INDIA \\ ${ }^{2}$ Associate Professor, Department of Economics, St. Joseph's College, Devagiri, INDIA
}

\begin{abstract}
This paper examines the nature of volatility of selected sectoral stock indices traded in the National Stock Exchange. Using the EGARCH model introduced by Nelson, it has been observed that the selected indices are subject to Autoregressive Conditional Heteroskedasticity $(A R C H)$ effects. There are significant leverage effects in the case of five indices. Volatility seems to be highly persistent in the case of all the indices except one. Moreover, four indices are highly sensitive to market events.
\end{abstract}

Keywords:

Autoregressive Conditional Heteroskedasticity, Exponential ARCH, Volatility.

Cite This Article: T. Mohamed Nishad, and K.T. Thomachan, "HOW VOLATILE IS INDIAN STOCK MARKET? A STUDY BASED ON SELECTED SECTORAL INDICES” International Journal of Research - Granthaalayah, Vol. 3, No. 12(2015): 142-149.

\section{INTRODUCTION}

Savings are generated when a person or an organization abstains from present consumption for a future use. Investment involves the commitment of resources which have been saved in the hope of some positive return. Donald E. Fischer and Ronald J. Jordan defined investment as "a commitment of funds made in the expectations of some positive rate of return."

The objective of investor is to maximize the return and minimize the risk from investment. Our savings as cash are not only a deadwood as they don't earn anything, but also lose its value to the extent of rise in prices. So savings are invested to provide hedge against inflation.

One may invest in physical assets or financial assets. A physical asset is an item of economic, commerce or exchange value that has tangible or material existence. For example, Land \& Building, Gold, Silver etc., financial asset is an asset that derives value because of a contractual claim. For example, Govt. securities, Post office savings, Fixed deposits, Bonds, Mutual funds, shares etc., 
Research studies prove that equity share returns have outperformed the returns of most other forms of investment in the long run. Equities have the potential to increase in value over time. Share represents the form of fractional ownership in business venture. Total equity capital of a company is divided into equal units of small denominations, each called a share. As the share is giving more return, it is more risky also.

Volatility is a statistical measurement of up and down asset price fluctuations over time. If an asset has rapid dramatic price swings, volatility will be high. If prices are consistent and rarely change volatility is low. It is a symptom of a highly liquid stock market. Pricing of securities depends on volatility of each asset. An increase in stock market volatility brings a large stock price change of advances or declines. Investors interpret a raise in stock market volatility as an increase in the risk of equity investment and consequently they shift their funds to less risky assets. It has an impact on business investment spending and economic growth through a number of channels. The issues of volatility have become increasingly important in recent times to the Indian investors, regulators, brokers, policy makers, dealers and researchers. According to Merton Miller, the Nobel laureate, writes "by volatility public seems to mean days when large market movements, particularly down moves, occur. These precipitous market wide price drops cannot always be traced to a specific news event. Nor should this lack of smoking gun be seen as in any way anomalous in market for assets like common stock whose value depends on subjective judgment about cash flow and resale prices in highly uncertain future. The public takes a more deterministic view of stock prices; if the market crashes, there must be a specific reason."

\section{STATEMENT OF THE PROBLEM}

Every investor faces a tradeoff between investing in risky and risk free assets. A risk free asset ensures a monetary flow that is known with certainty. A risky asset, on the other hand, provides a monetary flow that is at least in part random. This uncertainty about the monetary flow from a risky asset necessitates an estimation of the risk associated with every asset as a safeguard against large losses from investing in them. Of all the investments, investment in stock market is considered to be the most risky. On any given day, the price of an individual stock can go up or down by a large amount causing large gains or losses. As noted by Philip Hanes Franses, "since such financial time series reflect the result of trading among buyers and sellers at, for example, stock markets, various sources of news and other exogenous economic events may have an impact on the time series pattern of asset prices. Given that news can lead to various interpretations, and also given that specific economic events like an oil crisis can last for some time, we often observe the large positive and large negative observations in financial time series to appear in clusters."1 The riskiness of an asset can be measured by the stock market volatility, the swings in the prices of individual stocks or indices of a group of stocks.

${ }^{1}$ Philip Hanes Franses, Time Series Models for Business and Economic Forecasting, Cambridge University Press, New York, 1988, P. 155.

Financial time series such as stock prices, interest rates, foreign exchange rates, inflation rates etc. often exhibits phenomenon of volatility clustering; that is, periods of turbulence in which their prices show wide swings and periods of tranquility in which there is relative calm. Thus there is a concentration of periods of high and low volatility. An average investor is not only 
concerned about the rate of return on his investment but also about the risk of investment as well as the variability or volatility of risk. Thus it is important to measure not only the asset price but also asset returns and volatility of asset returns.

A simple measure of asset return volatility is its variance overtime. However, this measure of volatility will not take into account past history of returns; that is, it will not take into account time varying volatility in asset returns. An investor who buys an asset at time period $t$ and plans to sells it at $t+1$ is not only interested in the rate of return alone but also the variance of the rate of return during the holding period. Thus the investor has to know the conditional variance during the holding period.

Forecasting the variance of returns is of interest for many reasons. Variance of an asset price is a measure of the risk of owning the asset. The larger the variance of daily stock price changes, the more a stock market participant stands to gain or loss on a typical day. Moreover, the value of some financial derivatives such as options depends on variance of the underlying asset. For example, the volatility of stock market prices enters directly in to the Black - Scholes formula for deriving the prices of traded options. This aim of this paper is to examine the volatility of selected sectoral stock indices traded in the Indian stock market.

\section{OBJECTIVES}

a) To assess the extent of volatility among selected sectoral stock indices.

b) To examine the persistence of shocks among the selected indices

c) To evaluate whether there is any asymmetry in the effect of positive and negative shocks among the selected indices.

\section{REVIEW OF LITERATURE}

Anpukarasi and Nithya (2014) ${ }^{\mathbf{1}}$ in their study, they examine return and volatility of the Indian sectoral indices. They used the tools like descriptive statistics, auto correlation and exponential trend to analyse the data. The study found the correlation is significant for most of the indices.

Shanmugasundram and Benedict $(2013)^{2}$ the study attempts to find out the volatility of the Indian sectoral indices. They selected the tools like ANOVA \& $\mathrm{t}$ test to indentify the risk factor difference among the sectoral indices \& Nifty. It is found that there is no difference in the standard deviation among various sectoral indices $\&$ there is a significant difference in the mean scores of various time intervals.

Lakshmi P (2013) 3 explores in her study volatility pattern of various sectoral indices in Indian stock market. She used the ARCH model to measure the volatility in Nifty and various other sectoral indices. The study found that the realty sector has the higher volatility than any other sector in India Market.

Islam $(2013)^{4}$ attempt to estimate volatility of stock index return. He used GARCH models to estimate volatility of three Asian markets Indonesia, Malaysia \& Singapore. He found that Indonesian Market is more Volatile than the other two markets. 


\section{DATA AND METHODOLOGY}

The study is based on daily data on selected sectoral indices for the period January 3, 2011 to October 30, 2015. Sectoral indices selected are automobile (Auto), banking sector (Bank), energy sector (Energy), finance sector (Finance), information technology (IT), metallurgy (Metal), fast moving consumer goods (FMCG) industries and Pharmacy (Pharma). Since our concern is volatility of returns of stock indices, all the sectoral indices are used in log difference form to model the mean and variance equation.

There are various measures of volatility. Modeling and forecasting volatility is perhaps the most important area of research in the whole of finance in the last two decades. Volatility, as measured by the standard deviation or variance of returns is often used as a crude measure of the total risk of financial assets. It involves calculating the variance or standard deviation of returns in the usual way over some historical period and this then becomes the volatility forecast for all future time periods. This volatility, however, will not take in to account time varying volatility in asset returns. Thus we want a measure of volatility that changes overtime. Such a measure of time varying volatility known as Autoregressive Conditional Heteroskedasticity (ARCH) was first suggested by Engle (1982). The original model was later extended in many directions. In 1986, Bollerslev suggested a generalization of $\mathrm{ARCH}$ known as Generalized Autoregressive Conditional Heteroskedasticity (GARCH).

GARCH specification is very popular because it fits many data series well. Another popular specification is the GARCH in mean or GARCH - M model introduced by Engle, Lilien and Robins (1987). This model specifies return itself as a function of variance. The basic idea is that return to risky assets will be higher than return to safe assets to compensate the investor for taking more risk. In this specification conditional variance enters in to the conditional expectation as an additional factor determining mean returns.

One basic problem with GARCH models is that they treat symmetric response of volatility to both positive and negative shocks. It is argued that there is an asymmetry in the response of volatility of financial time series to positive and negative shocks. A negative shock is likely to cause volatility to rise by more than positive shock of same magnitude. (This asymmetry in financial literature is known as 'leverage effects') Two popular models of asymmetry are the Threshold GARCH (TGARCH) model introduced by Glosten, Jagannathan and Runkle (1993) and Exponential GARCH (EGARCH) model introduced by Nelson (1991).

Though TGARCH model treats positive and negative shocks asymmetrically unlike ARCH and GARCH and GARCH-M models, this model is also based on the restriction that the parameters will be greater than or equal to zero. EGARCH model has no such restrictions. The model not only treats positive and negative shocks asymmetrically, but also ensures that the estimated coefficients are positive. The variance specification for EGARCH model is:

$$
\log (h t)=\lambda+\sum_{j=1}^{q} \alpha j\left|\frac{U t-j}{\sqrt{h t-j}}\right|+\sum_{j=1}^{q} \gamma j \frac{U t-j}{\sqrt{h t-j}}+\sum_{j=1}^{p} \delta i \log (h t-j)
$$


In this specification, the variable $\frac{U t-j}{\sqrt{h t-j}}$ captures the relative size of the shocks and $\left|\frac{u t-j}{\sqrt{h t-j}}\right|$ captures the relative magnitude of the shocks. The $\alpha$ parameter represents a magnitude effect or the symmetric effect of the model, the "GARCH" effect. $\delta$ measures the persistence in conditional volatility irrespective of anything happening in the market. When $\delta$ is relatively large, then volatility takes a long time to die out following a shock in the market. The $\gamma$ parameter measures the asymmetry or leverage effect. If $\gamma$ is zero, then the model is symmetric. If $\gamma$ is less than zero, then positive shocks (good news) generate less volatility than negative shocks (bad news). If $\gamma$ is greater than zero, positive shocks cause an increase in volatility than negative shocks.

The normal EGARCH models do not tend to fit financial returns in which market shocks have non normal conditional distributions. Market returns typically have leptokurtic conditional distributions. Thus we use EGARCH-GED (generalized error) model than simple EGARCH model.

\section{EMPIRICAL ANALYSIS}

We present below the result of the empirical analysis carried out on the sectoral indices beginning with a plot of the return series of all the indices. The plot of the return series clearly shows the presence of ARCH effects.
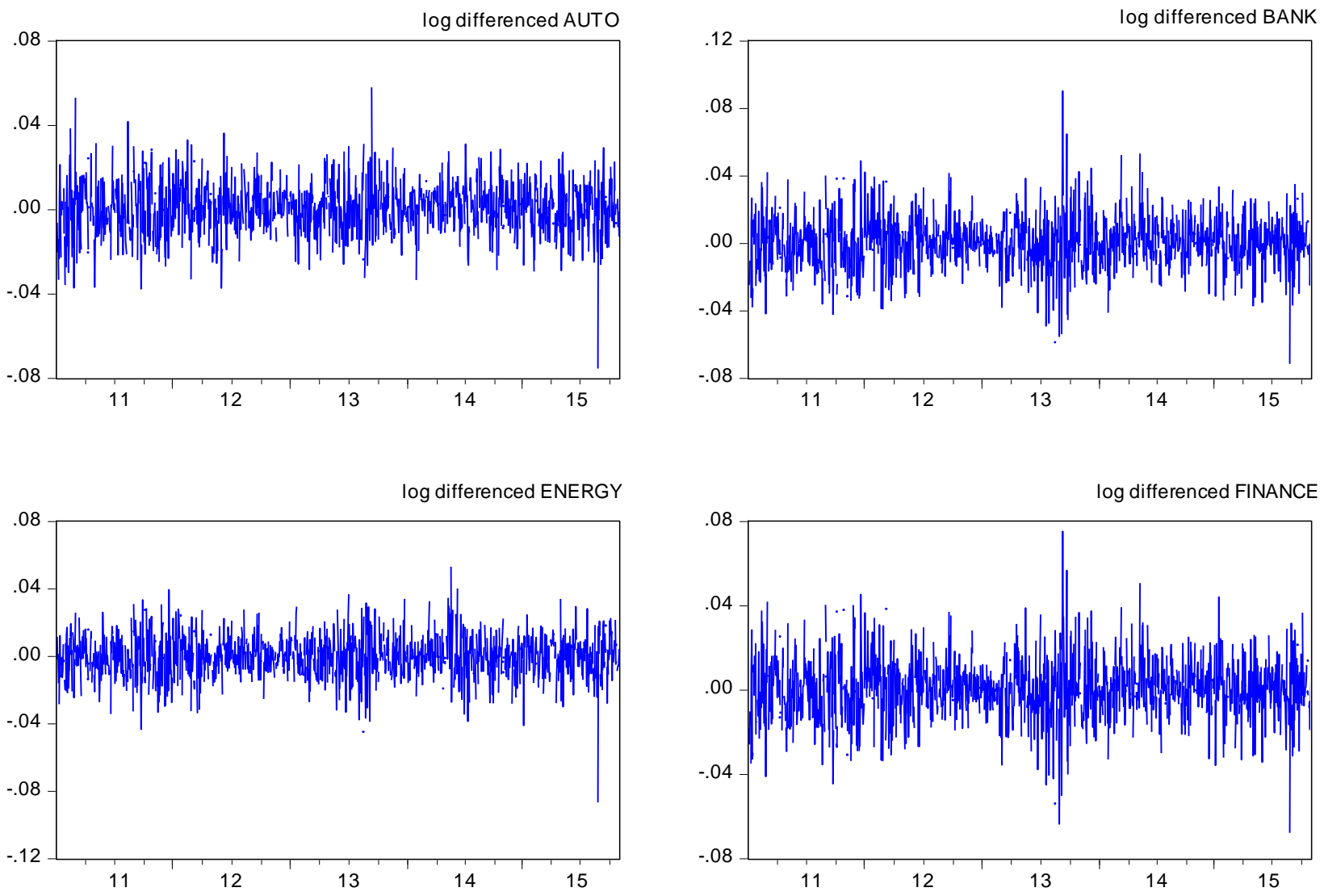

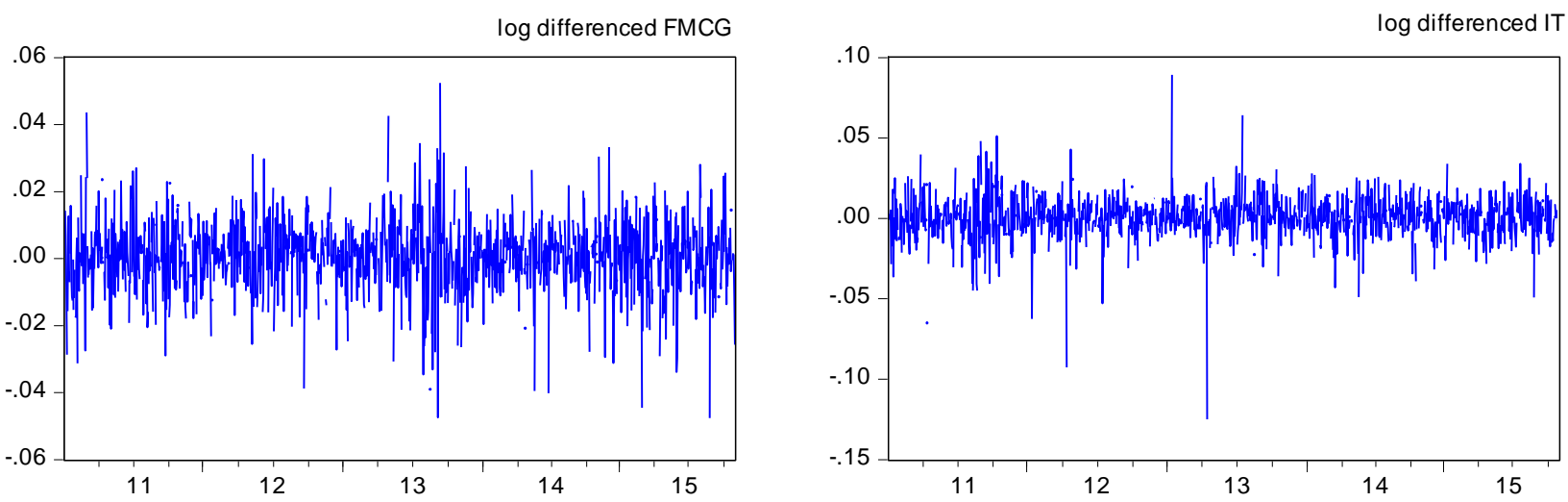

log differenced MEDIA

log differenced METAL
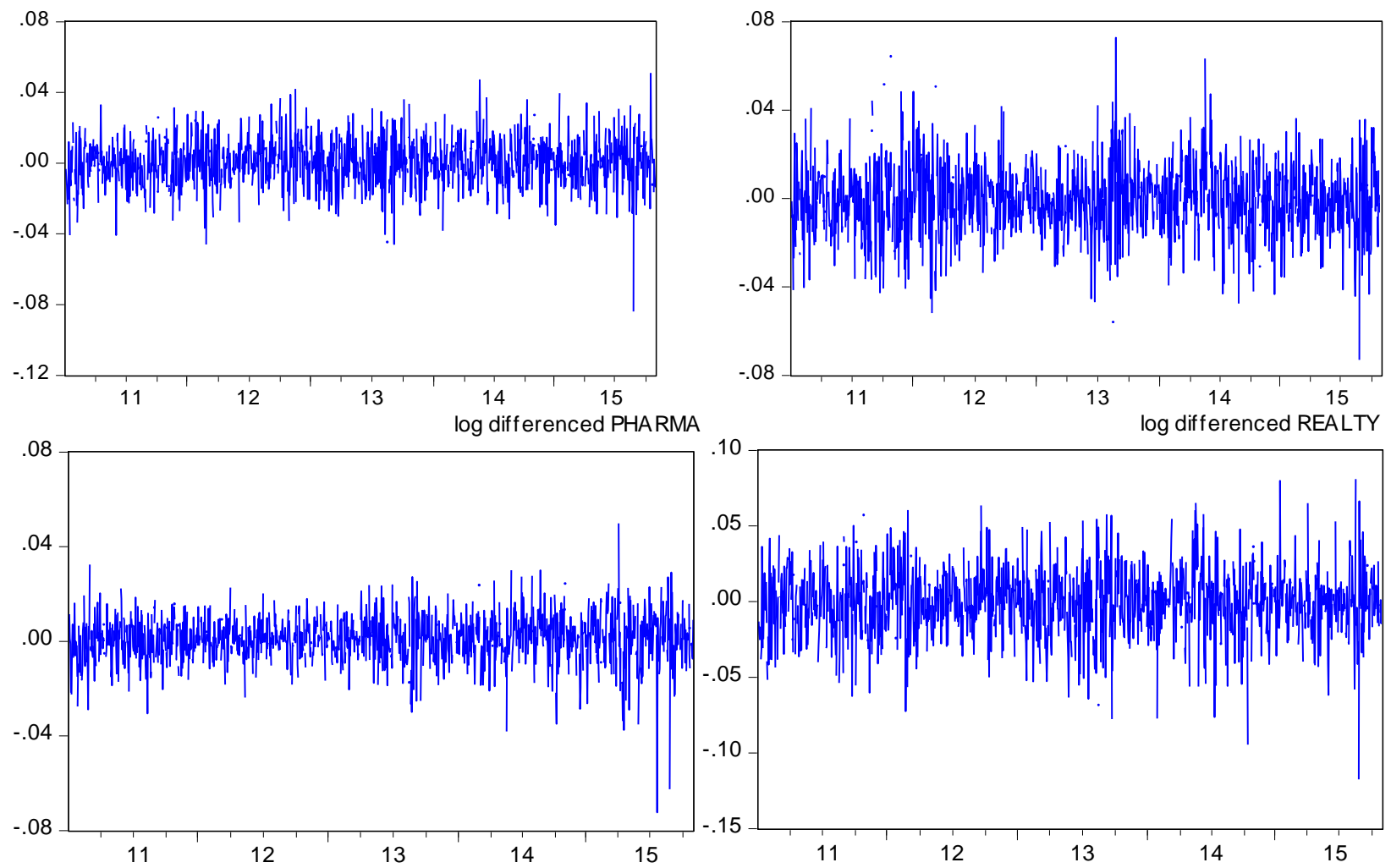

To further investigate, the presence of ARCH effect, ARCH LM test has been employed on the return series of all the indices. The mean equation used is of the form $Y t=\mu+\varepsilon t$ where $\mathrm{Y}$ is the $\log$ difference series, $\mu$ is a constant and $\varepsilon$ is the stochastic error term. The test results are presented in Table 1.

Table 1: Test result of ARCH Effects

\begin{tabular}{|l|l|}
\hline Sectoral Indices & ARCH LM $(\chi \mathbf{2})$ Test \\
\hline AUTO & $8.789223(0.0325)^{*}$ \\
\hline BANK & $23.19387(0.0001)^{* *}$ \\
\hline ENERGY & $13.86296(0.0001)^{* *}$ \\
\hline FINANCE & $26.19876(0.00000)^{* *}$ \\
\hline FMCG & $21.17427(0.0003)^{* *}$ \\
\hline IT & $16.45236(0.0045)^{* *}$ \\
\hline
\end{tabular}




\begin{tabular}{|l|l|}
\hline MEDIA & $28.52056(0.0274)^{*}$ \\
\hline METAL & $9.61234(0.0082)^{* *}$ \\
\hline PHARMA & $15.53195(0.0037)^{* *}$ \\
\hline REALTY & $21.92596(0.0002)^{* *}$ \\
\hline
\end{tabular}

Figures in brackets are $\mathrm{P}$ values

** indicates significance at $1 \%$ level, * indicates significance at $5 \%$ level

Table 1 clearly shows that there are significant ARCH effects in the return series of all the sectoral indices during the time period under consideration. Having established the presence of ARCH effects, we proceed to estimate the EGARCH model for all the series. The results of the coefficients from fitting the EGARCH model are presented in Table 2.

Table 2: Test result of EGARCH coefficients

\begin{tabular}{|l|l|l|l|l|}
\hline Sectoral Indices & $\lambda$ & \multicolumn{1}{|c|}{$\boldsymbol{\alpha}$} & \multicolumn{1}{c|}{$\boldsymbol{\gamma}$} & \multicolumn{1}{c|}{$\boldsymbol{\delta}$} \\
\hline AUTO & -0.606858 & 0.0999028 & -0.087761 & 0.940047 \\
& $(0.0003)^{* *}$ & $(0.0056)^{* *}$ & $(0.0000)^{* *}$ & $(0.0000)^{* *}$ \\
\hline BANK & -0.200455 & 0.067640 & -0.047394 & 0.982180 \\
& $(0.0002)^{* *}$ & $(0.0002)^{* *}$ & $(0.0000)^{* *}$ & $(0.0000)^{* *}$ \\
\hline ENERGY & -0.439269 & 0.128833 & -0.031488 & 0.961214 \\
& $(0.0123)^{* *}$ & $(0.0001)^{* *}$ & $(0.0492)^{* *}$ & $(0.0000)^{* *}$ \\
\hline FINANCE & -0.232326 & 0.064009 & -0.064416 & 0.978381 \\
& $(0.0000)^{* *}$ & $(0.0106)^{* *}$ & $(0.0000)^{* *}$ & $(0.0000)^{* *}$ \\
\hline FMCG & -0.36249 & 0.086528 & -0.018551 & 0.0967276 \\
& $(0.0535)$ & $(0.0057)^{* *}$ & $(0.3899)$ & $(0.0000)^{* *}$ \\
\hline IT & -1.166406 & 0.154798 & -0.04573 & 0.878477 \\
& $(0.0283)^{* *}$ & $(0.0031)^{* *}$ & $(0.1360)$ & $(0.0000)^{* *}$ \\
\hline MEDIA & -0.979256 & 0.083265 & -0.035133 & 0.893524 \\
& $(0.1681)$ & $(0.0586)$ & $(0.1437)$ & $(0.0000)^{* *}$ \\
\hline METAL & -0.301131 & 0.124435 & -0.045717 & 0.975304 \\
& $(0.0031)^{* *}$ & $(0.0000)^{* *}$ & $(0.0011)^{* *}$ & $(0.0000)^{* *}$ \\
\hline PHARMA & -0.116476 & 0.064511 & 0.008289 & 0.992645 \\
& $(0.0487)^{* *}$ & $(0.0017)^{* *}$ & $(0.5082)$ & $(0.0000)^{* *}$ \\
\hline REALTY & -1.031650 & 0.161429 & -0.023069 & 0.880129 \\
& $(0.0287)^{* *}$ & $(0.0008)^{* *}$ & $(0.3391)$ & $(0.0000)^{* *}$ \\
\hline
\end{tabular}

Figures in brackets are $\mathrm{P}$ values

** indicates significance at $5 \%$ level

The parameter estimates are presented in table 2. The leverage effect $\gamma$ are negative and significant for AUTO, BANK, ENERGY, FINANCE and METAL. It shows that in the case of these indices good news generates less volatility than bad news. No leverage effect has been observed in the case of remaining commodities. The parameter $\alpha$ is significant for all the indices except MEDIA. It shows that volatility is sensitive to market events. A comparison of various indices show that REALTY, METAL, IT and ENERGY are highly sensitive to market events compared to other indices. Though media is statistically significant at $5 \%$ level, it is significant at $10 \%$ level. $\delta$ measures the persistence in conditional volatility. It is clear from the table that all the coefficients are statistically significant at 5\% level. It also show that except FMCG, the 
coefficient estimates are very high suggesting that it takes a long time to volatility to settle down following a shock.

\section{CONCLUSION}

This paper considered the modeling of the stock returns volatility of selected sectoral indices from the National Stock Exchange, NIFTY. ARCH LM $(\chi 2)$ Test confirmed the presence of ARCH effect in all the sectoral indices. To test the nature of volatility EGARCH model has been fitted to all the indices. Leverage effect is found to be significant in the case of AUTO, BANK, ENERGY, FINANCE and METAL. REALTY, METAL, IT and ENERGY are highly sensitive to market events compared to other indices. Except in the case of FMCG, volatility seems to be highly persistent. This is evident from the high value of the coefficient $\delta$.

\section{REFERENCES}

[1] Dr. M. Anbukarasi and B. Nithya, "Return and Volatility Analysis of the Indian Sectoral Indices- with special reference to National Stock Exchange”, EPRA international Journal of Economic \& Business Review, Vol. 2, Issue - 8, pp 90-97, August 2014.

[2] Dr. G Shanmugasundaram and D John Benedict, "Volatility of the Indian sectoral indices - A study with reference to National Stock Exchange”, Indian Journal of marketing, Financial services and Management research, Vol.2, No.8, pp 1-11, August 2013.

[3] Swarna Lakshmi P, "Volatility pattern in various sectoral indices in Indian Stock Market”, Global Journal of Management \& Business Studies, Vol.3, No.8, pp 880-884, 2013.

[4] Mohd. Aminul Islam, "Estimating Volatility of Stock Index Returns by using symmetric GARCH models”, Middle-East Journal of Scientific Research, 18 (7), pp 991 - 999, 2013.

[5] Bollerslev. $T$ (1986) - Generalized Autoregressive Conditional Heteroskedasticity, Journal of Econometrics, 33(1), 307-327.

[6] Enders, Walter (2010) - Applied Econometric Time Series, third edition, Wiley student edition.

[7] Engle. R F (1982) - Autoregressive Conditional heteroskedasticity with Estimates of the Variance of United Kingdom Inflation, Econometrica, 987-1007.

[8] Engle R. F, Lilien D M, Robins R P (1987) - Estimating Time Varying Risk Premia in the Term Structure: The ARCH - Model, Econometrica 55, PP 251-76

[9] Glosten L.R, Jogannathan R, Runkle D (1993) - Relations between the expected expected nominal stock excess return; the volatility of the nominal excess return and the interest rate, Journal of Finance 48(5), PP 1779-801

[10] Nelson D B (1991) - Conditional heteroskedasticity in Asset Returns; A new Approach, Econometrica, 59, PP 347-50. 